\title{
Modeling of shimmy oscillations in aircraft landing gear
}

\author{
Hristina Georgieva ${ }^{1, *}$ \\ ${ }^{1}$ Technical University - Sofia, Aeronautical Department, 8 Kliment Ohridski Blvd., 1000 Sofia, Bulgaria
}

\begin{abstract}
The paper proposes an analysis of shimmy oscillations in one of the most used aircraft in general aviation. The main goal of the research is to develop a mathematical model with three degrees of freedom created in a Matlab environment on a Cessna Citation M2. The parameters of the model are obtained from Cessna Textron Aviation, Goodyear Aviation tires and scientific studies. Present research focuses on three main areas: 1) mathematical model, 2) numerical application and results, and 3) discussion and conclusion. The results obtained are presented graphically to facilitate the study of landing gear shimmy oscillations. The effects observed present the subject of discussions in the paper. The model makes the optimisation of the amplitude and time of shimmy oscillation possible.
\end{abstract}

\section{Introduction}

Aircraft landing gears may experience self-excited oscillation in lateral and torsional direction, known as shimmy oscillations, caused by the interaction between the tyres and the ground. Shimmy oscillations appear in aircraft ground dynamics during taxing, take-off and landing. They can be found on both the nose and main landing gear, but the first occurrence is more common. Shimmy oscillations are usually not catastrophic but they can reduce landing gear stability and result in serious problems (excessive wear, shortened life cycle of gear parts, safety concerns, discomfort for pilots and passengers or eventually lead to an accident) [1-3]. Shimmy oscillations may occur due to wheel imbalance, torsional freeplay, inadequate torsional stiffness, etc.

In order to increase the understanding of these oscillations on aircraft landing gear researchers have elaborated different shimmy models. One of earliest contribution to shimmy dynamics was reported by Broulhiet in 1925 [4]. In the study the role of tyre flexibility and side slip in the shimmy mechanism was recognized. Smiley [5] investigated shimmy oscillations for three different landing gear structures. The nonlinear geometric effects were not included in the model while one of the cases had a non-zero rake angle. The paper included linear stability of a landing gear model and discussed a systematic way of modelling the strut geometrical aspects. Somieski described shimmy oscillations as a nonlinear phenomenon for a nose landing gear with zero rake angle [6]. Woerner and Noel [7] explain the main cause of shimmy oscillations is the energy transfer from the contact force between the tyres and the ground to the vibrational modes of the landing gear system. This stability depends on the damping and stiffness characteristics of tyres and the supporting structure.
The developed models of shimmy oscillations are mainly based on different number of degrees of freedom, different analysis methods and different ways of modelling the elastic tyres [8-14]. These models allow for the analysis of the stability and the response of shimmy oscillations.

Shimmy oscillations are a problem in the design and operation of aircraft landing gears, especially in general aviation aircraft. This aircraft can be used as a business jet or aircraft for special missions such as aerial survey, air ambulance, flight inspection and surveillance. This required an accurate and appropriate analysis in order to increase their safety during ground motion. Cessna is a representative of this type of aircraft in general aviation.

The aim of this research is to study the impact of the vertical force on the gear, taxiing velocity of the aircraft and torsional angle on the amplitude and the time of the shimmy oscillations in the aircraft nose landing gear and their optimisation. To do this, the paper proposes a mathematical model on a Cessna Citation M2 with three degrees of freedom created in a Matlab environment.

\section{Mathematical model of shimmy oscillation in aircraft landing gear}

\subsection{Aircraft nose landing gear}

The geometry of aircraft nose landing gear is shown in Fig. 1 , where positive $X$-axis is the rear direction of the aircraft, the $Z$-axis is the upward to the ground and the $Y$ axis completes the right-handed coordinate system. The nose landing gear consists of a wheel with a pneumatic tyre with radius $R$ mounted on an axle that is attached to a strut via a mechanical caster with length $e$. The strut axis is inclined to the vertical at the rake angle $\varphi$. The applied vertical force $F_{z}$ on the gear represents the combined

\footnotetext{
* Corresponding author: hgeorgieva@tu-sofia.bg
} 
effect of the fuselage and wings. The aircraft moves with a forward velocity $V_{x}$.

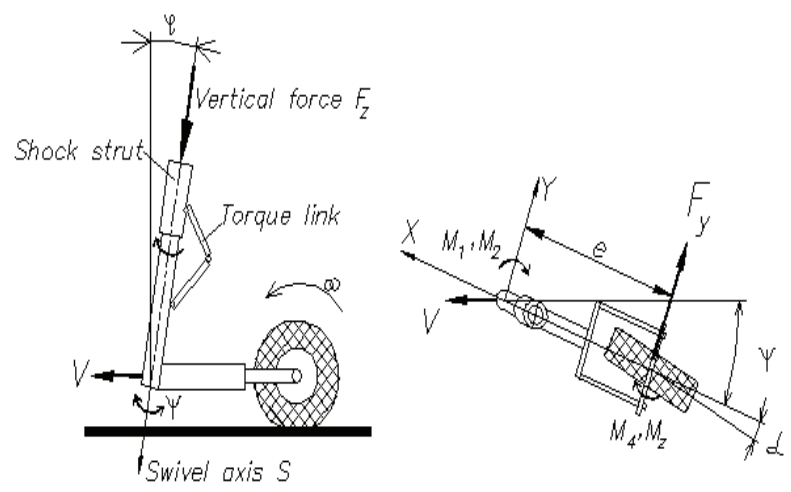

Fig. 1. Side and top view of the nose landing gear.

The model has three degrees of freedom:

- The rotation of the gear around the strut axis $S$ (torsional mode) described by the torsional angle $\psi$;

- The bending of the gear around the X-axis, (lateral mode) described by angle $\delta$;

- The two modes are coupled through the tyre-ground interaction. The present work uses the stretched string tyre model developed by von Schippe and Dietrich [15]. The model defines the nonlinear kinematic relationship between the torsional angle $\psi$, lateral bending angle $\delta$ and the lateral deformation $\lambda$ of the leading edge of the tyre contact patch.

The presence of a non-zero rake angle $\varphi$ has several important geometrical effects in an aircraft nose landing gear [8]. It involves an effective caster length $e_{\text {eff }}$ that is given by:

$$
e_{e f f}=e \cos \varphi+R \tan \varphi+e \sin \varphi \tan \varphi
$$

The wheel swivel angle $\theta$ with the ground is different from the steering angle and it is expressed by:

$$
\theta=\psi \cos \varphi .
$$

When the steering angle $\psi$ is non-zero there is also a tilt of the wheel:

$$
\gamma=\psi \sin \varphi .
$$

In this paper the effect of this angle is not considered.

The vertical force $F_{z}$ is offset from the $\mathrm{X}-\mathrm{Z}$ plane due to the effective caster length $e_{\text {eff, }}$ which creates a moment that destabilizes the orientation of the gear.

The equations of motion for the model of the nose landing gear, taking into account torsional and lateral motion and their coupling via the elastic tyre can be written as:

$\mid \begin{aligned} & I_{z} \ddot{\psi}=M_{K \psi}+M_{D \psi}+M_{F 1}+M_{D \alpha}+F_{z} \sin \varphi e_{e f f} \sin \theta ; \\ & I_{x} \ddot{\delta}=M_{K \delta}+M_{D \delta}+M_{\lambda \delta}+M_{D \alpha}+F_{z} e_{e f f} \sin \theta ; \\ & \dot{\lambda}=V \sin \theta+l_{g} \dot{\delta} \cos \delta-(V / L) \lambda+\left(e_{e f f}-h\right) \cos \theta \dot{\psi} \cos \varphi,\end{aligned}$

where the dimensions are given in Table 1.
The moment $M_{K \psi}$ corresponding to the torsional stiffness of the strut is a function of the steering angle $\psi$ and is defined by:

$$
M_{K_{\psi}}=k_{\psi} \psi
$$

The moment $M_{D \psi}$ due to the torsional damping of the strut is a function of the steering angular velocity $\dot{\psi}$ and is expressed by:

$$
M_{D \psi}=c_{\psi} \dot{\psi}
$$

where $k_{\psi}$ and $c_{\psi}$ are the torsional stiffness and damping coefficients of the strut.

The self-aligning torsional moment $M_{K \alpha}$ about the strut is given by:

$$
M_{K \alpha}=\mid \begin{array}{ll}
F_{z n} k_{\alpha} \frac{\alpha_{m}}{\pi} \sin \left(\alpha \frac{\alpha_{m}}{\pi}\right) & \text { if }|\alpha| \leq \alpha_{m} \\
0 & \text { if }|\alpha|>\alpha_{m}
\end{array}
$$

where $k_{\alpha}$ is the self-aligning coefficient of the tyre and $\alpha_{m}$ is the limit of the self-aligning moment.

The lateral restoring force $F_{K \lambda}$ of the tyre is defined as:

$$
F_{K \lambda}=k_{\lambda} \tan ^{-1}\left\{7 \tan (\alpha) \cos \left[0,95 \tan ^{-1} 7 \tan (\alpha)\right]\right\} F_{z n},
$$

where $k_{\lambda}$ is the restoring coefficient of the tyre.

The tyre slip angle $\alpha$ is related to the lateral deformation $\lambda$ by:

$$
\lambda=\operatorname{atan} \frac{\lambda}{L}
$$

where $L$ is the relaxation length of the tyre.

The combined moment $M_{F 1}$ due to the tyre restoring force $F_{K \lambda}$ and self-aligning moment $M_{K \alpha}$ that are functions of the tyre lateral deformation $\lambda$ is given by

$$
M_{F 1}=M_{K \alpha}-e_{e f f} F_{K \lambda} \text {. }
$$

The moment $M_{D \lambda}$ due to the tyre lateral damping is given by:

$$
M_{D \lambda}=c_{\lambda} \dot{\psi} \cos \varphi
$$

where $c_{\lambda}$ is the lateral damping coefficient of the tyre.

The moment $M_{K \delta}$ due to the lateral bending stiffness of the strut is function of $\delta$ and is expressed by:

$$
M_{K \delta}=k_{\delta} \delta
$$

where $k_{\delta}$ is the lateral bending stiffness of the strut.

The moment $M_{D \delta}$ due to the damping characteristics of the strut is function of $\dot{\delta}$ and is given as:

$$
M_{D \delta}=c_{\delta} \dot{\delta}
$$

where $c_{\delta}$ is the damping coefficient of the lateral bending of the strut. 
The moment $M_{\lambda \delta}$ is the result of the force created from the lateral deformation of the tyre and is given as:

$$
M_{\lambda \delta}=l_{g} F_{K \lambda} \cos \theta \cos \varphi,
$$

where $l_{g}$ is the distance between the nose landing gear attachment point in the fuselage and the ground.

\subsection{Aircraft data source}

The parameters of the model are obtained from $\mathrm{G}$. Somieski, 1997 [6], P. Thota et al., 2008 [8], Cessna Textron Aviation [16], Goodyear Aviation tires [17] and are presented in Table 1.

Table 1. System parameters for modelling.

\begin{tabular}{|c|c|c|}
\hline Parameter & Value & Unit \\
\hline \multicolumn{3}{|c|}{ Structure parameters } \\
\hline Caster length, $e$ & 0,1 & $\mathrm{~m}$ \\
\hline Gear height, $l_{g}$ & 1,0 & $\mathrm{~m}$ \\
\hline Strut torsional stiffness, $k_{\psi}$ & $-1,10^{5}$ & Nm.rad ${ }^{-1}$ \\
\hline Strut torsional damping, $c_{\psi}$ & -45 & Nm.s.rad ${ }^{-1}$ \\
\hline $\begin{array}{c}\text { Strut moment of inertia about } \\
z \text {-axis, } I_{z} \\
\end{array}$ & 1 & $\mathrm{~kg} \cdot \mathrm{m}^{2}$ \\
\hline Strut later bending stiffness, $k_{\delta}$ & $-3,24.10^{6}$ & Nm.rad ${ }^{-1}$ \\
\hline Strut later bending damping, $c \delta$ & -150 & Nm.s.rad ${ }^{-1}$ \\
\hline $\begin{array}{l}\text { Strut moment of inertia about } \\
x \text {-axis, } I_{x}\end{array}$ & 1 & $\mathrm{~kg} \cdot \mathrm{m}^{2}$ \\
\hline Rake angle, $\varphi$ & 4 & $\mathrm{rad}$ \\
\hline \multicolumn{3}{|c|}{ Tyre parameters } \\
\hline Radius of nose wheel, $R$ & 0,2286 & $\mathrm{~m}$ \\
\hline Contact patch length, $h$ & 0,1 & $\mathrm{~m}$ \\
\hline $\begin{array}{l}\text { Elastic tyre damping } \\
\text { coefficient, } c_{\lambda}\end{array}$ & -270 & $\mathrm{Nm}^{2} \mathrm{rad}^{-1}$ \\
\hline $\begin{array}{l}\text { Elastic tyre self-aligning } \\
\text { coefficient, } k_{\alpha}\end{array}$ & -2 & $\mathrm{~m} / \mathrm{rad}$ \\
\hline $\begin{array}{l}\text { Elastic tyre restoring } \\
\text { coefficient, } k \lambda\end{array}$ & 20 & $\mathrm{rad}^{-1}$ \\
\hline Relaxation length, $L$ & 0,2 & $\mathrm{~m}$ \\
\hline Self-aligning moment limit, $\alpha_{m}$ & 0,1745 & $\mathrm{rad}$ \\
\hline \multicolumn{3}{|c|}{ Continuation parameters } \\
\hline Vertical force on the gear, $F_{z n}$ & $8-13$ & $\mathrm{kN}$ \\
\hline Forward velocity, $V_{x}$ & $90-70$ & $\mathrm{~m} / \mathrm{s}$ \\
\hline
\end{tabular}

\section{Numerical simulation and results}

A numerical simulation with Matlab software is performed in order to analyse the behavior of the proposed model for studying the shimmy oscillations in the nose landing gear defined by equation (4).

Three different simulations are studied.

- Simulation 1: In this simulation, the system is supposed to have a constant vertical force of $F_{z}=4491 \mathrm{~kg}$ on the gear, representing values of the maximum landing weight (MLW);
- Simulation 2: The system in this simulation is subjected to a constant vertical force of $F_{z}=3831 \mathrm{~kg}$ on the gear corresponding to $80 \%$ of MLW;

- Simulation 3: In this simulation, the system received a constant vertical force of $F_{z}=3171 \mathrm{~kg}$ on the gear, representing values of the basic operating weight (BOW);

The three simulation cases are run with taxiing velocity $V_{x}$ changing from 70 to $90 \mathrm{~m} / \mathrm{s}$ and disturbance yaw angle $\psi=0,3 \mathrm{rad}$.

To obtain the amplitude of the cycle, simulation over a time of 1 second is made. From the time histories we can record the amplitude as function of varied parameters: taxiing velocity $V$, vertical force of the gear $F_{z}$, damping constant of the strut $c_{\psi}$ and disturbance yaw angle $\psi$.

Figures 2-10 show some of the results about the lateral tyre deflection $\lambda$, the lateral bending angle $\delta$ and the phase plot of shimmy angle $\psi$ for the second case of simulation.

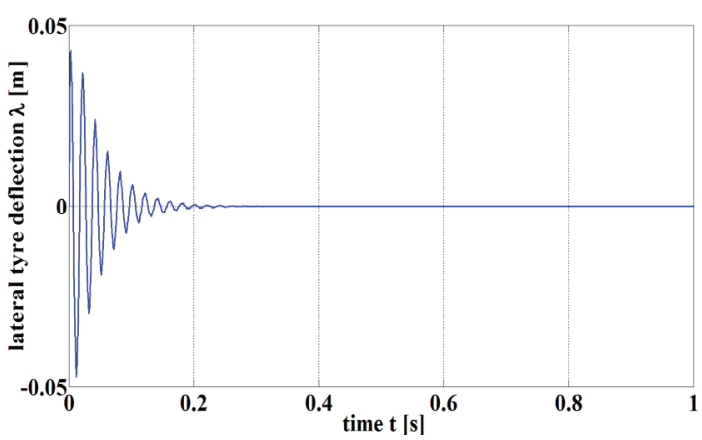

Fig. 2. Modelled lateral tyre deflection for: $F_{z n}=10690 \mathrm{~N}, V_{x}=90 \mathrm{~m} / \mathrm{s}, \psi=0,3 \mathrm{rad}$.

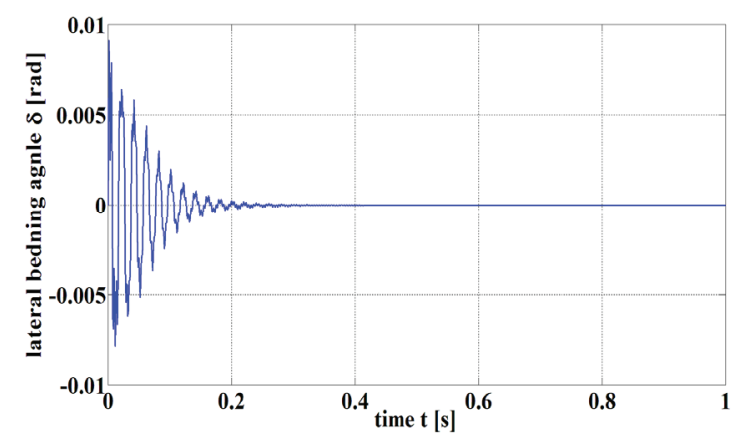

Fig. 3. Modelled bending angle of tyre: $F_{z n}=10690 \mathrm{~N}, V_{x}=90 \mathrm{~m} / \mathrm{s}, \psi=0,3 \mathrm{rad}$.

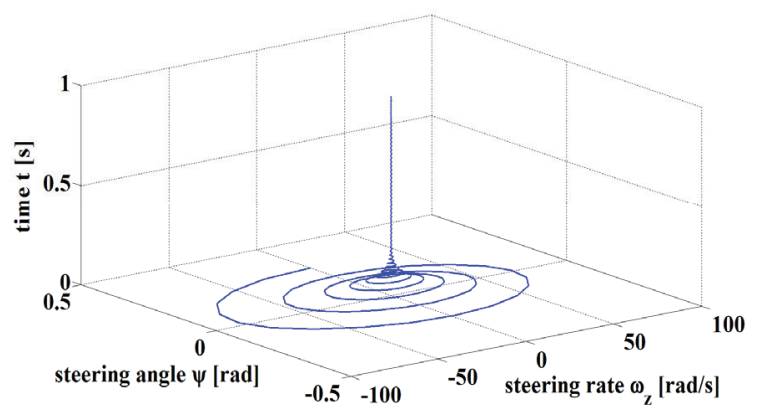

Fig. 4. Modelled phase plot of shimmy yaw angle for: $F_{z n}=10690 \mathrm{~N}, V_{x}=90 \mathrm{~m} / \mathrm{s}, \psi=0,3 \mathrm{rad}$. 


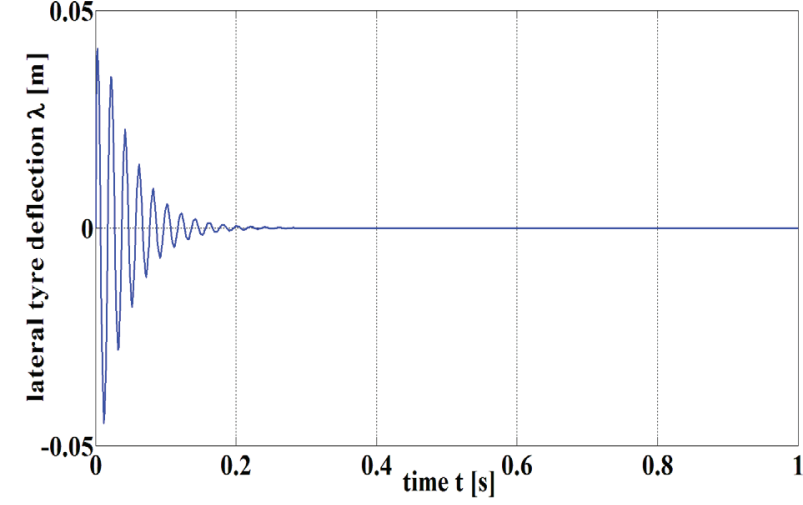

Fig. 5. Modelled lateral tyre deflection. $\mathrm{F}_{\mathrm{zn}}=10690 \mathrm{~N}, \mathrm{~V}_{\mathrm{x}}=80 \mathrm{~m} / \mathrm{s}, \psi=0,3 \mathrm{rad}$.

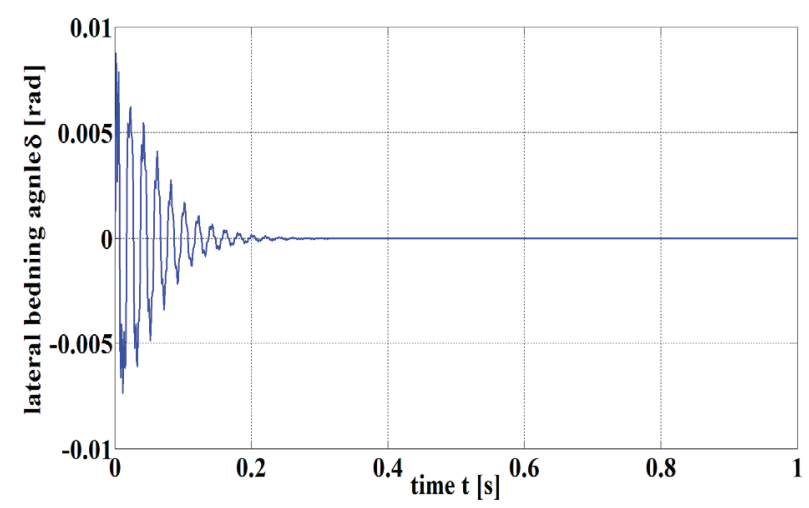

Fig. 6. Modelled bending angle of tyre: $F_{z n}=10690 \mathrm{~N}, V_{x}=80 \mathrm{~m} / \mathrm{s}, \psi=0,3 \mathrm{rad}$.

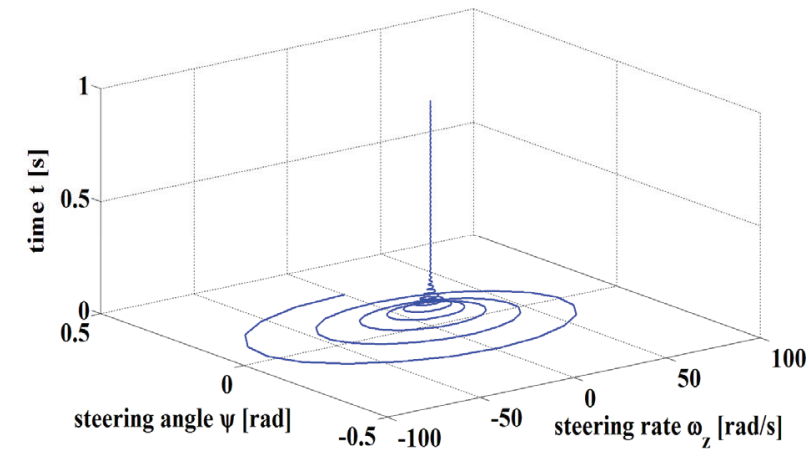

Fig. 7. Modelled phase plot of shimmy yaw angle. $F_{z n}=10690 \mathrm{~N}, V_{x}=80 \mathrm{~m} / \mathrm{s}, \psi=0,3 \mathrm{rad}$.

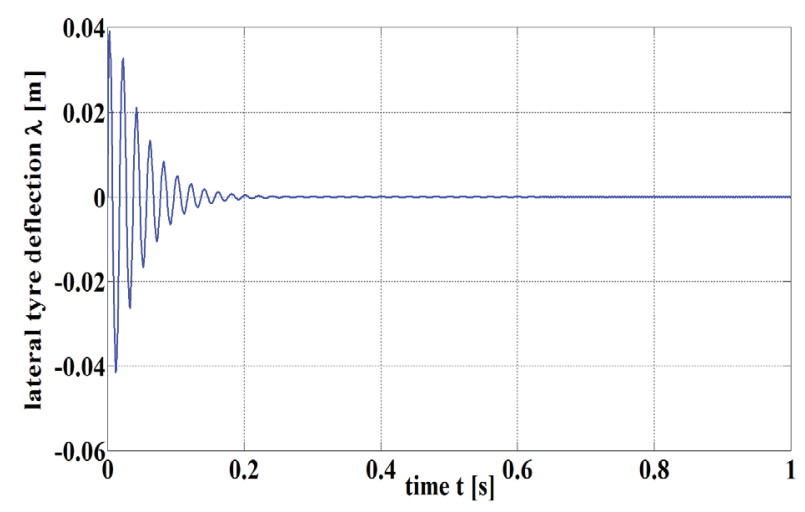

Fig. 8. Modelled lateral tyre deflection. $F_{z n}=10690 \mathrm{~N}, V_{x}=70 \mathrm{~m} / \mathrm{s}, \psi=0,3 \mathrm{rad}$.

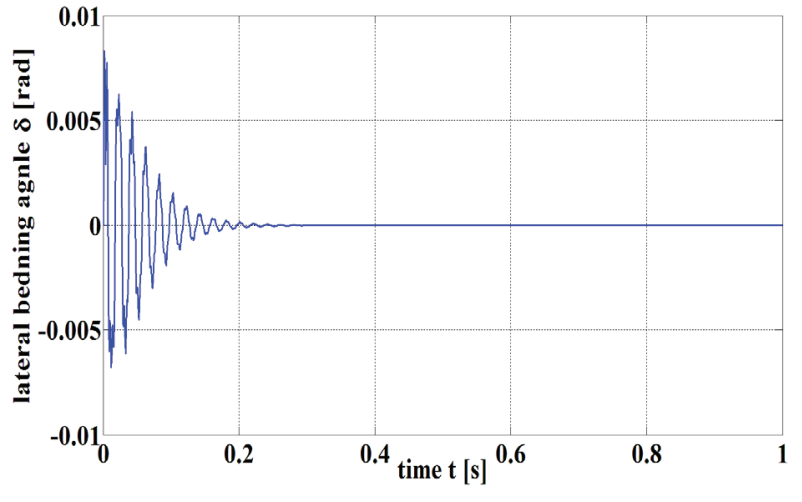

Fig. 9. Modelled bending angle of tyre: $F_{z n}=10690 \mathrm{~N}, V_{x}=70 \mathrm{~m} / \mathrm{s}, \psi=0,3 \mathrm{rad}$.

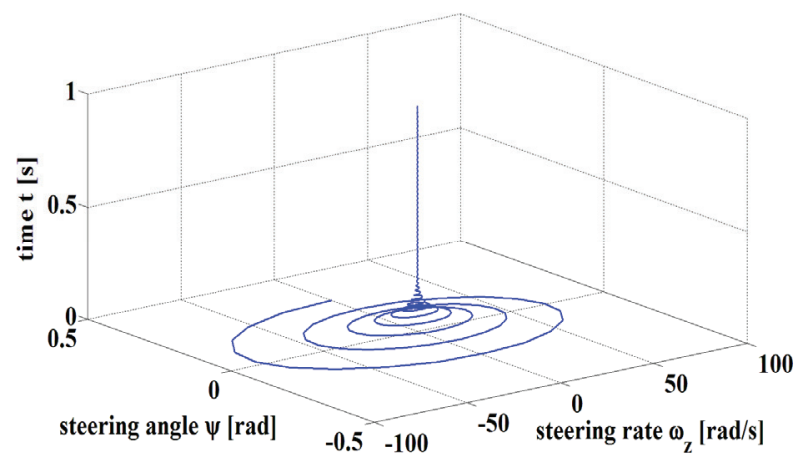

Fig. 10. Modelled phase plot of shimmy yaw angle. $F_{z n}=10690 \mathrm{~N}, V_{x}=70 \mathrm{~m} / \mathrm{s}, \psi=0,3 \mathrm{rad}$.

Figure 11 shows unstable case (MLW and taxiing velocity $V_{x}=90 \mathrm{~m} / \mathrm{s}$ ) of the lateral tyre deflection $\lambda$.

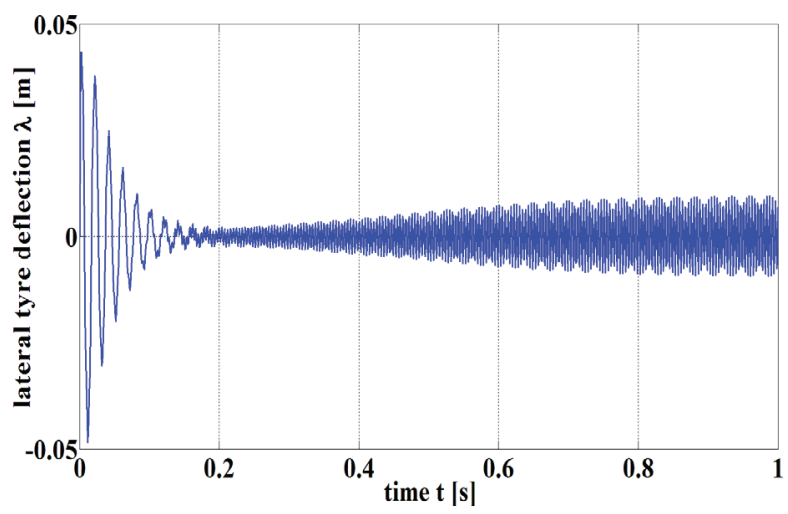

Fig. 11. Modelled lateral tyre deflection. $F_{z n}=12531 \mathrm{~N}, V_{x}=90 \mathrm{~m} / \mathrm{s}, \psi=0,3 \mathrm{rad}$.

Table 2 presents the results about the amplitude $\lambda_{A}$ and the time of shimmy oscillations $t_{d}$ for all simulation cases. 
Table 2. Obtained simulation results.

\begin{tabular}{|c|c|c|c|c|c|c|c|}
\hline \multicolumn{2}{|c|}{$F_{z}, \mathrm{~N}^{V_{x}, \mathrm{~m} / \mathrm{s}}$} & \multicolumn{2}{|c|}{90} & \multicolumn{2}{|c|}{80} & \multicolumn{2}{|c|}{70} \\
\hline \multirow{2}{*}{$\begin{array}{l}\bar{n} \\
\stackrel{n}{2} \\
\mathcal{I}\end{array}$} & $\lambda_{A}, \mathrm{~m}$ & 0,043 & \multirow{2}{*}{ 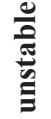 } & 0,042 & \multirow{2}{*}{$\frac{0}{\frac{0}{0}}$} & 0,039 & \multirow{2}{*}{$\frac{0}{0}$} \\
\hline & $t_{d}, \mathrm{~s}$ & - & & 0,960 & & 0,340 & \\
\hline \multirow{2}{*}{ 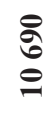 } & $\lambda_{A}, \mathrm{~m}$ & 0,043 & \multirow{2}{*}{$\begin{array}{l}\frac{0}{0} \\
\frac{\pi}{\pi}\end{array}$} & 0,042 & \multirow{2}{*}{$\frac{\frac{0}{0}}{\frac{\pi}{\pi}}$} & 0,039 & \multirow{2}{*}{$\frac{0}{\frac{0}{\pi}}$} \\
\hline & $t_{d, \mathrm{~s}}$ & 0,310 & & 0,290 & & 0,280 & \\
\hline \multirow{2}{*}{$\begin{array}{l}1 \\
\infty \\
\infty \\
\infty\end{array}$} & $\lambda_{A}, \mathrm{~m}$ & 0,043 & \multirow{2}{*}{$\frac{\frac{0}{0}}{\frac{\pi}{5}}$} & 0,042 & \multirow{2}{*}{$\frac{0}{\frac{0}{E}}$} & 0,039 & \multirow{2}{*}{$\frac{\frac{0}{0}}{\frac{\pi}{5}}$} \\
\hline & $t_{d, \mathrm{~S}}$ & 0,290 & & 0,280 & & 0,270 & \\
\hline
\end{tabular}

\section{Discussion and Conclusions}

The paper proposes a mathematical model applied on a Cessna Citation M2 nose landing gear for shimmy oscillations. The parameters of the model are obtained from Cessna Textron Aviation, Goodyear Aviation tires and scientific studies (G. Somieski, 1997, P.Thota et al., 2008).

The model has three degrees of freedom and allows to study the influence of the gear vertical force, aircraft taxiing velocity and torsional angle on the amplitude and time of shimmy oscillations and their optimization.

The optimal value of shimmy oscillations are: the amplitude $\lambda_{A}=(0,042-0,039) \mathrm{m}$ and time $t_{d}=(0,29-0,27)$ $\mathrm{s}$ can be found in the interval of taxiing velocity $V_{x}=(70-$ $80) \mathrm{m} / \mathrm{s}$, aircraft weight interval $F_{z}=$ (BOL- $80 \%$ from the MLW) N, torsional damping coefficient $c_{\psi}=-45 \mathrm{Nms} / \mathrm{rad}$ and torsional angle $\psi=0,3 \mathrm{rad}$.

The model shows that in the case of $M L W$ and taxiing velocity $V_{x}$ higher than $80 \mathrm{~m} / \mathrm{s}$ the system becomes instable.

The model gives also the possibility to study the impact of the rake angle, caster length and the strut torsional damping coefficient on the amplitude and time of shimmy oscillations and their optimization.

The proposed mathematical model is simple and this decreases computation times

The model that is presented in this work is generic and appropriated for the aircraft with single-wheel nose landing gear in the context of study of shimmy oscillations.

Future work will include study of more degrees of freedom like longitudinal bending, the effect of gyroscoping coupling of the tyre and duel-wheel configuration of the landing gear. Modelling of the change of the aircraft trajectory under the shimmy oscillations is also planned.

The final goal would be the formulation of an integrated mathematical model of a generic unmanned aerial vehicle.

\section{References}

1. Bureau d'acquêtes et d'Analysais pour la sécurité de l'aviation civile, Rapport accident (2011)
2. South African Civil Aviation Authority, Aircraft accident rapport and executive summary (2015)

3. La Comisión de Investigación de Accidentes e Incidentes de Aviación Civil, Technical Report A068/1999 (2006)

4. M. Broulhiet. La suspension de la direction de la voiture automobile - Shimmy et dandinement, Bull. Soc. Ing. Civ., France, 78, (1925)

5. R. Smiley, Correlation, evaluation, and extension of linearized theories for tire motion and wheel shimmy, NACA tech. rep, 1299, Washington, DC, (1957)

6. G. Somieski, Shimmy analysis of a simple aircraft nose landing gear model using different mathematical methods, Aerospace Science and Technology, 8, 1270-9638, (1997)

7. P. Woerner, O. Noel, Influence of nonlinearity on the shimmy behaviour of landing gear, 81st Meeting of the AGARD Structures and Materials Panel, AGARD-R800, (1995)

8. P. Thota, B. Krauskopf, M. Lowenberg, Shimmy in a nonlinear model of an aircraft nose landing gear with non-zero rake angle, ENOC-2008, Saint Petersurg, Russia, 30 June - 4 July, (2008)

9. P. Thota, B. Krauskopf, M. Lowenberg, Interaction of torsion and lateral bending in aircraft nose landing gear shimmy, Nonlinear Dynamics, 57(3), 455-467, (2009)

10. P. Thota, B. Krauskopf, M. Lowenberg, Bifurcation analysis of nose landing gear shimmy with lateral and longitudinal bending, J. Aircraft, 47, 87-95, (2010)

11. I. Besselink, Shimmy of aircraft main landing gears, Dissertation, University of Delft, The Netherlands, (2000)

12. E. Coetzee. Shimmy in Aircraft Landing Gear, Technical report, Problem presented by Airbus http://www.smithinst.ac.uk/Projects/ESGI56/ESGI5AirbusShimmy/Report (2006)

13. C. Howcrof, B. Krauskopf, M. Lowenberg, S. Neild, Influence of variable side-stay geometry on the shimmy dynamics of an aircraft dual-wheel main landing gear. SIAM Journal on applied dynamical systems, 12(3), 1181-1209, (2013)

14. C. Howcroft, M. Lowenberg, S. Neild, B. Krauskopf, E. Coetzee, Shimmy of an aircraft main landing gear with geometric coupling and mechanical freeplay, ASME. J. Comput. Nonlinear Dynam, 10(5), (2014)

15. B. Schlippe, R. Dietrich, Shimmying of a pneumatic wheel", NACA-TM 1365, (1947)

16. Cessna Textron Aviation,www.cesssna.txtav.com/en, last accessed: 15 September, 2017

17. Goodyear Aviation Tires, www.goodyearaviation.com/index.html, last accessed: 15 September, 2017 